\title{
Semi-Rigid Cast versus Elastic Bandage in the Grade II Lateral Ankle Sprain Treatment
}

\author{
${ }^{1}$ Andri Primadhi* ${ }^{(D)},{ }^{1}$ Ghuna A. Utoyo, ${ }^{1}$ Hermawan Nagar Rasyid ${ }^{(D)}$ \\ ${ }^{1}$ Department of Orthopaedics and Traumatology, Universitas Padjadjaran Medical School, Hasan Sadikin \\ Hospital, Bandung, Indonesia.
}

Submitted 02 May 2020; Accepted in final form 01 July 2020.

\begin{abstract}
Background. Treatment options for lateral ankle sprains continue to evolve as advances are made in terms of techniques and materials. Objectives. This study was performed to evaluate clinical outcomes and satisfaction between two immobilization materials, semi-rigid cast, and elastic bandages. Methods. This study was a non-randomized controlled study. Fifty-four patients have undergone immobilization for their sprained ankle and divided into two groups according to the material selection. There were 27 patients in each group. VAS score, Karlsson score, satisfaction scale, and presence of later ankle instability was obtained. Standard descriptive measurement, independent samples t-test, and chi-square test were used for statistical analysis. Results. The mean age was $25.29 \pm 6.04$ years old. Sports injury was accounted for 27 patients $(50 \%)$, followed by internal damage (24 patients; $44.4 \%)$. VAS and Karlsson's scores were taken and validated by authors and significantly better in semi-rigid cast groups compared with the elastic bandage group in the first week and second-week follow-up. No significant differences in overall satisfaction and ankle stability after one year. Conclusion. This study showed that the application of semi-rigid cast yielded quicker recovery in patients with ankle sprain without any decline in satisfaction scale. Therefore, a semi-rigid cast could be preferred over elastic bandage for acute ankle sprains.
\end{abstract}

\section{KEYWORDS: Ankle Sprain, Semi-Rigid Cast, Elastic Bandage, Instability, Athletes}

\section{INTRODUCTION}

An ankle sprain is one of the most common injuries encountered by orthopedic surgeons, with a high incidence among physically active individuals, accounting for 2.15 per 1000 persons per year in the United States, in which the peak incidence occurred between fifteen and nineteen years of age $(1,2)$. Ankle sprains account for $45 \%$ of all injuries in basketball, and up to $31 \%$ in soccer (3). Additionally, acute ankle sprains have a high recurrence rate, which is associated with the development of chronic ankle instability (CAI) (2). The mean total costs of an ankle sprain were estimated at $€ 360.60$, resulting from medical consumption, rehabilitation, persistent residual symptoms, and high recurrence rates (4). This relatively high cost of treatment means that cost- effective methods for treatment are required for ensuring healthcare sustainability. Injury to the ligaments can result in laxity of the ankle complex, but neuromuscular deficits are also likely to occur due to damage to the nervous and musculotendinous tissue (5).

Additionally, the abnormal formation of scar tissue after an injury can lead to sinus tarsi syndrome or anterolateral impingement syndrome, which can lead to functional instability of the ankle complex (5). Impairment in the ankle region could disturb the overall locomotion, hence sufficient and appropriate treatment is mandatory. It had been generally accepted that nonsurgical treatment is the mainstay of management for the vast majority of an ankle sprain,

*. Corresponding Author:

Andri Primadhi, Assistant Professor

E-mail: randri@unpad.ac.id 
even in the athletic population (6). The first phase of treatment includes protection, rest or restricted activity, ice, compression, and elevation (PRICE). The compression component of the PRICE method is combined with various degrees of immobilization, from ankle taping to ankle stirrups, walking boots, plaster splinting, or casting (7).

Ankle ligament sprains are usually graded based on severity. Grade I is a mild stretching of the ligaments without macroscopic rupture or joint instability. Grade II (moderate) is a partial rupture of the ligament with moderate pain and swelling. Grade III (severe) is a complete ligament rupture with marked pain, swelling, hematoma, and pain (8).

Treatment options for these injuries continue to evolve as advances are made in terms of techniques and materials, but the optimum management is still open to debate. In most emergency departments, patients are given an elastic support bandage, but in some departments, a wool and crepe wrap round bandage is used $(9,10)$. Recent evidence has shown the need for more stringent immobilization to facilitate ligament healing and restoration of joint stability and function (10).

Semi-rigid cast is a relatively new material that can reduce some of the problems of rigid cast immobilization, with ease of application and removal. Avci and Sayli compared soft cast, and rigid cast for acute ankle sprain grade III revealed that soft cast was found to be at least as effective as the rigid one. Swelling, pain and instability were comparable in both groups, and semi-rigid cast groups had a better range of motion and higher satisfaction at two weeks (11). Petersen et al. concluded grade I and II ankle sprains might best be treated with semi-rigid braces (6). Diversely, when compared with the splint, an elastic bandage was preferred for the treatment of acute ankle sprains and proven more effective in reducing edema (12). Those findings showed us that the material rigidity was not the sole determinant of the treatment outcome. From another point of view, the unit cost of the semi-rigid cast is generally lower than the ankle brace.

To the best of our knowledge, there was no prior comprehensive study conducted on outcomes of semirigid cast application for type II ankle sprain compared with an elastic bandage. This study aimed to analyze whether acute ankle inversion sprain could be better treated in the semi-rigid cast in comparison with an elastic bandage, with the least incidence of further ankle instability.

\section{MATERIALS AND METHODS}

A non-randomized controlled study of ankle sprain's treatment was undertaken at Orthopaedic Foot and Clinics, Hasan Sadikin Hospital, Bandung, Indonesia, over one year (January 2018 - December 2018). The inclusion criteria were: (1) acute inversion ankle sprain grade II with less than one-day onset, and (2) patients age 18 - 45 years. The exclusion criteria were: (1) recurrent ankle sprain during follow-up periods, (2) previous inappropriate treatment, e.g., by traditional bone setter, (3) open wound presentation, (5) patient with generalized joint laxity, confirmed with Beighton hypermobility score, and (6) had prior significant pathology around the ankle, e.g., fracture or ligament problems.

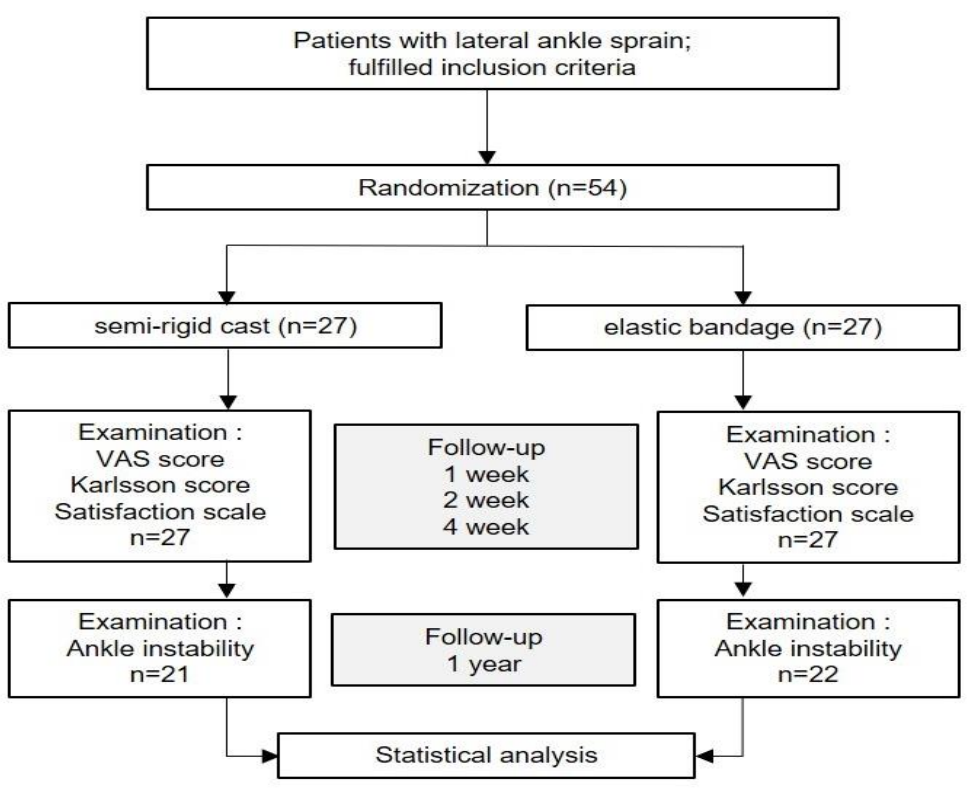

Figure 1. Flow Chart of the Study 
Fifty-four patients met the criteria and treated by either semi-rigid casting or elastic bandaging (Figure 1). A simple grouping attempt was made by allocating each patient to either of the groups at the time of admission. The arranged follow up visits for this study were one-week, two-weeks, one-month, and one-year post-treatment. All patients had appropriate clinical assessments according to the classification system (Table 1) before a decision was made.

Table 1. Clinical Classification System for Lateral Ankle Sprain (8)

\begin{tabular}{|c|c|}
\hline Grade & Remark \\
\hline I & No loss of function, no ligamentous laxity, little or no hemorrhaging, no point tenderness \\
\hline II & $\begin{array}{l}\text { Some loss of function, positive anterior drawer test, negative talar tilt test, hemorrhaging, point tenderness, decreased total ankle } \\
\text { motion of } \leq 5^{\circ} \text { but }<10^{\circ} \text {, swelling }>0.5 \mathrm{~cm} \text { but }<2.0 \mathrm{~cm}\end{array}$ \\
\hline III & Near-total loss of function, positive anterior drawer and talar tilt test, hemorrhaging, extreme point tenderness \\
\hline
\end{tabular}

After considering the inclusion and exclusion criteria, we clustered the patients to the semi-rigid group and elastic bandage group. Deltacast ${ }^{\circledR}$ Soft (BSN Medical, Germany) and Tensocrepe ${ }^{\circledR}$ (BSN Medical, Germany) were used for semi-rigid casting and elastic bandaging, respectively, as shown in Figure 2. After application, all patients were advised not to bear weight at the affected side until one week after use. Then the patients are allowed for partial weight-bearing until the following week for cast/bandage removal. Clinical parameters consisted of a visual analog score (VAS) score, Karlsson score, and overall satisfaction scores were obtained at the initial visit, and each follows up visits. The patients were sent to the Physical Medicine, and Rehabilitation (PMR) Department for physiotherapy, including proprioception exercise and peroneal muscle strengthening after immobilization, was discontinued. At a one-year follow-up visit, the anterior drawer test was performed to point out any ankle instability (Figure 3).

Descriptive statistics (arithmetic means, averages, and ranges) were calculated using standard formulas. The clinical outcomes and satisfaction scales were then compared to ascertain for any statistically valid difference by an independent student's t-test. $\mathrm{P}$ values of $<0.05$ were considered significant. Statistical analysis was performed using software IBM SPSS version 25 and reviewed by an independent statistician.

The institutional review board approved this study of our hospital before commenced. The patient's informed consent, and departmental permission was obtained according to hospital regulations.

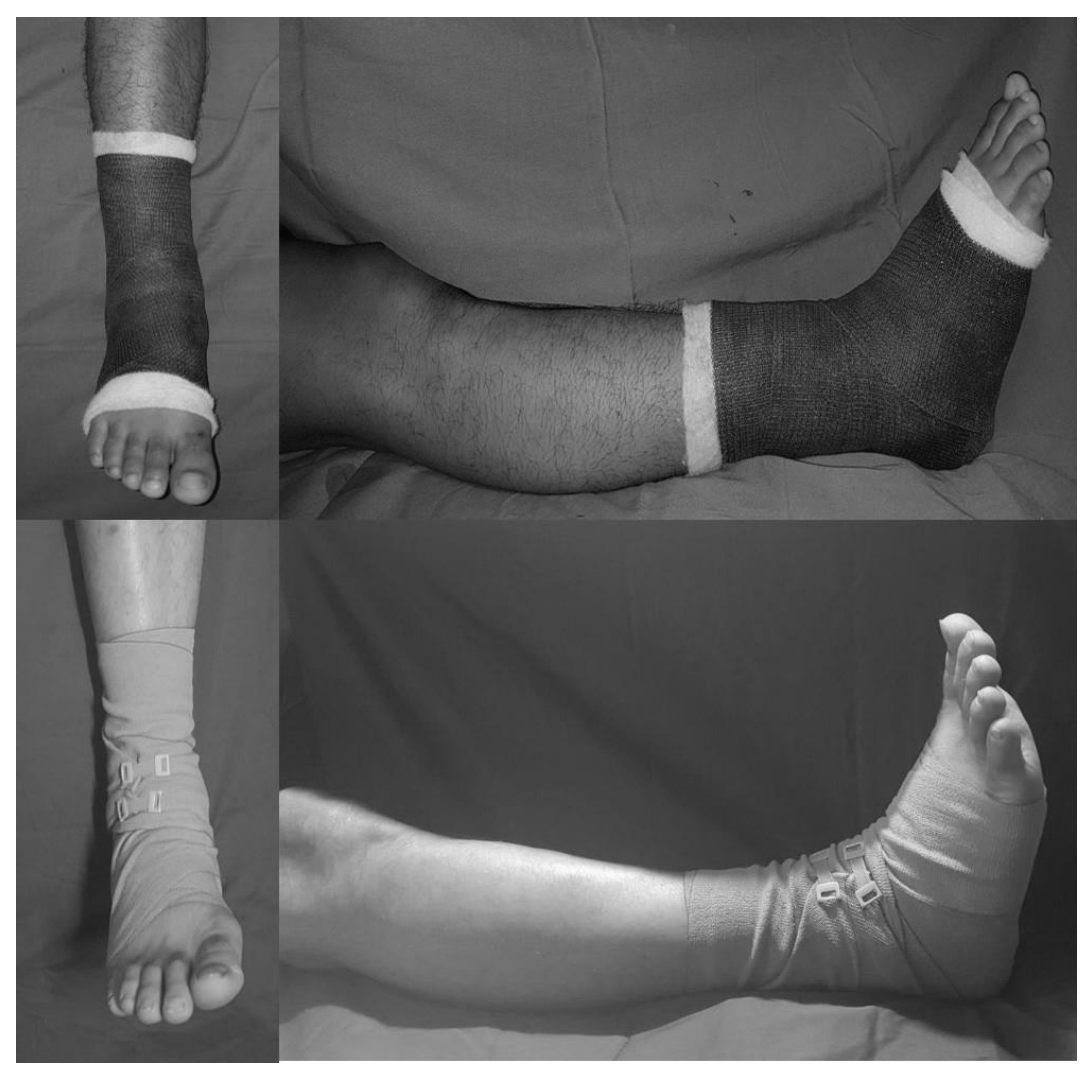

Figure 2. Clinical Pictures after Semi-Rigid Cast Applications (Upper) and Elastic Bandage (lower). The Bandage and Cast Were Wrapped around the Ball of the Foot, Then Slowly Circled the Arch of the Foot and Ankle, Keeping it Taut with a Light Pull. 


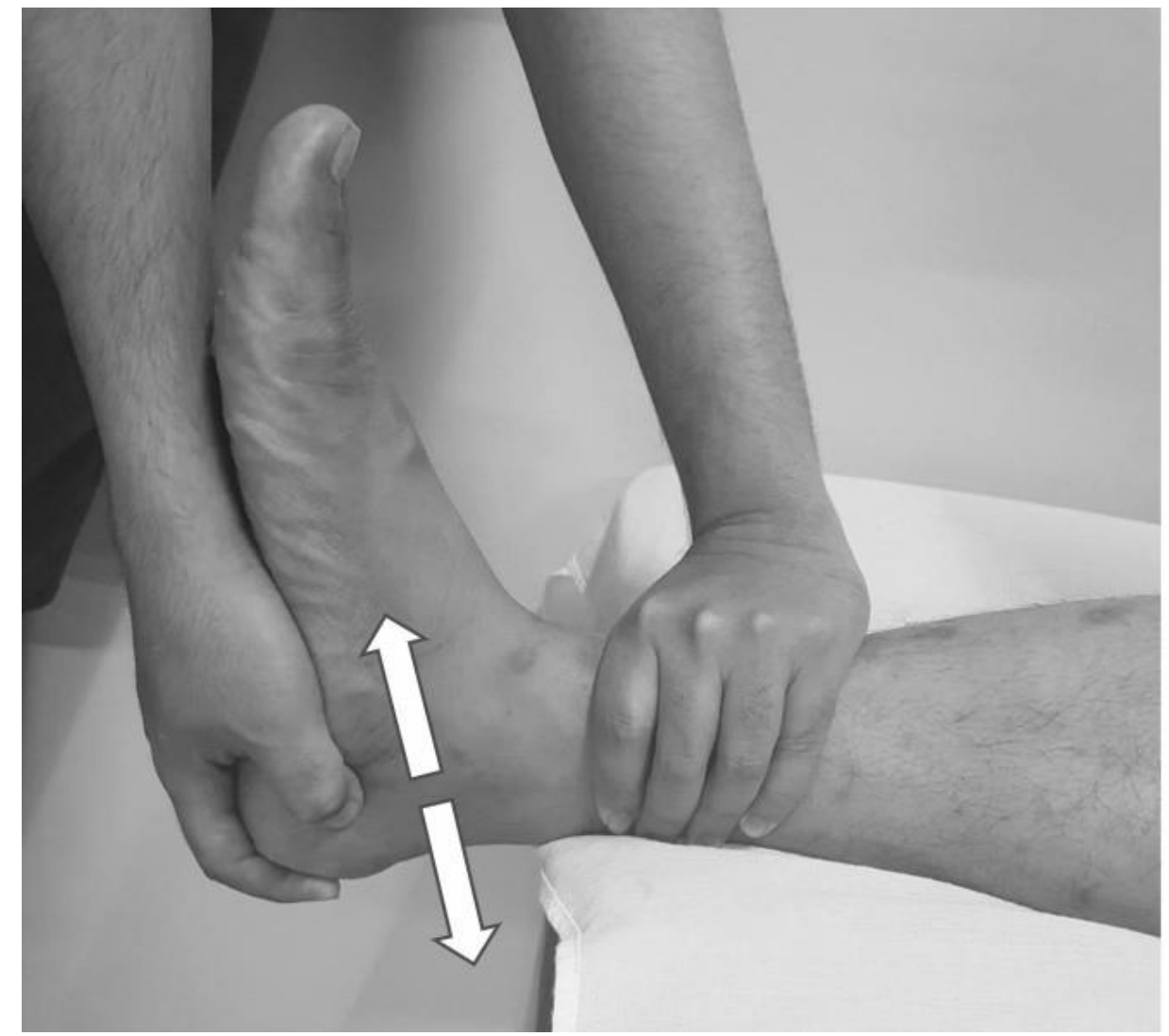

Figure 3. Anterior Drawer Test to Observe Ankle Instability

\section{RESULTS}

Patients Characteristics (Table 2). Among all fifty-four patients, the age range was 18 - 41 years old. The male to female ratio was accounted for 30:24 in all subjects. There was no apparent side predilection noted. Sport injury accidents accounted for about 50\% of all the patients, followed by internal injuries (44.4\%) and other causes (5.6\%). There were no remarkably associated medical problems found in all patients.

Clinical Results (Table 3). The clinical results were obtained from the examination at the clinic by the doctors in charge of using a standardized examination chart and validated by the authors. Our study showed clinical improvement in each group during the respective follow-up period. Statistically significant difference of VAS score and Karlsson score was found at first week $(\mathrm{P}=0.029$ and $\mathrm{P}=0.036$, respectively) and second week follow up visits, $(\mathrm{P}=0.002$ and $\mathrm{P}=$ 0.013 respectively). There was no significant difference in satisfaction scales between the two groups $(\mathrm{P}>0.05)$. At a one-year follow-up visit, the number of patients was decreased due to loss of follow-up. We found no significance between groups in terms of ankle instability result, despite more favorable results in the semi-rigid cast group ( $\mathrm{P}=$ 0.069).

Table 2. Patients Characteristics

\begin{tabular}{lccc}
\hline & Semi-Rigid Cast $\mathbf{N = 2 7}$ & Elastic Bandage $\mathbf{N}=\mathbf{2 7}$ & P Value \\
\hline Sex & & & 0.715 \\
$\quad$ Male & 15 & 15 & \\
$\quad$ Female & 12 & 12 & 0.608 \\
Age (mean: $25.29 \pm \mathbf{6 . 0 4}), \mathbf{y}$ & & & \\
$\quad<20$ & 4 & 4 & \\
$\quad \geq 20$ and $<30$ & 15 & 19 & \\
$\quad \geq 30$ and $<40$ & 7 & 2 & 0.765 \\
$\quad \geq 40$ & 1 & 2 & \\
Etiogy & 13 & 14 & 0.500 \\
$\quad$ Sports injury & 13 & 11 & \\
$\quad$ Domestic injury & 1 & 2 & \\
Others & & & \\
Laterality & 11 & 10 & \\
$\quad$ Left & 16 & 17 & \\
$\quad$ Right & & & \\
\hline
\end{tabular}


Table 3. Clinical Outcomes

\begin{tabular}{|c|c|c|c|}
\hline & Semi-Rigid Cast $^{\mathbf{a}}$ & Elastic Bandage $^{\mathrm{a}}$ & P Value \\
\hline \multicolumn{4}{|l|}{ VAS score } \\
\hline Initial & $6.67 \pm 0.73$ & $6.77 \pm 0.84$ & 0.609 \\
\hline $1^{\text {st }}$ week follow-up & $4.29 \pm 0.72$ & $4.77 \pm 0.84$ & 0.029 \\
\hline $2^{\text {nd }}$ week follow-up & $1.33 \pm 0.96$ & $2.22 \pm 1.01$ & 0.002 \\
\hline $4^{\text {th }}$ week follow-up & $0.85 \pm 0.66$ & $0.88 \pm 0.75$ & 0.848 \\
\hline \multicolumn{4}{|l|}{ Karlsson score } \\
\hline Initial & $27.66 \pm 7.18$ & $25.37 \pm 6.86$ & 0.235 \\
\hline $1^{\text {st }}$ week follow-up & $31.81 \pm 5.98$ & $29.51 \pm 6.22$ & 0.036 \\
\hline $2^{\text {nd }}$ week follow-up & $39.89 \pm 3.88$ & $37.14 \pm 3.95$ & 0.013 \\
\hline $4^{\text {th }}$ week follow-up & $74.78 \pm 6.65$ & $73.70 \pm 5.96$ & 0.966 \\
\hline \multicolumn{4}{|l|}{ Satisfaction scale } \\
\hline Initial & $4.37 \pm 0.49$ & $4.33 \pm 0.48$ & 0.781 \\
\hline $1^{\text {st }}$ week follow-up & $4.51 \pm 0.50$ & $4.59 \pm 0.50$ & 0.592 \\
\hline $2^{\text {nd }}$ week follow-up & $4.59 \pm 0.50$ & $4.48 \pm 0.50$ & 0.432 \\
\hline $4^{\text {th }}$ week follow-up & $4.62 \pm 0.49$ & $4.59 \pm 0.50$ & 0.785 \\
\hline Ankle instability after 1 year & $\mathrm{n}=11($ of 21$)$ & $\mathrm{n}=18($ of 22$)$ & 0.069 \\
\hline
\end{tabular}

${ }^{\mathrm{a} D a t a}$ are presented as mean $\pm \mathrm{SD}$.

\section{DISCUSSION}

Semi-rigid cast is a synthetic casting tape material, but unlike rigid cast, it has different polyurethane resin, which results in higher elasticity. Semi-rigid cast was designed to provide practical support to fractures and soft tissue injuries. Its semi-rigidity allows for more flexibility and mobility, thus helping to reduce immobilization-related problems such as atrophy or joint stiffness. Zmurko et al. had compared the structural and material properties of semi-rigid material, rigid material, and plaster of Paris (POP). Initial stiffness and yield force values of semi-rigid casts were significantly lower than for rigid cast and POP made of the same number of layers. The cast made from semi-rigid cast may be indicated for nonrigid applications, but not where rigid immobilization is required (13).

The main functions of ligaments are known to be mechanical, working as passive strains of bones in diarthrodial joints (14). The lateral ligamentous complex of the ankle consists of three ligaments: the anterior talofibular (ATFL), the calcaneofibular (CFL), and the posterior talofibular (PTFL). Each of the ligaments has a role in stabilizing the ankle joint. The most common ligament disruption by far involves the ATFL. In the biomechanical studies, the ATFL has a lower load to failure than does the CFL. It's lower maximum pressure to collapse, along with the shared mechanism of injury, helps to explain the higher frequency of injuries to the $\operatorname{ATFL}(15,16)$. Damage to the ligaments can result in the laxity of the ankle complex.

Additionally, the abnormal formation of scar tissue after the injury can lead to sinus tarsi syndrome or anterolateral impingement syndrome, which can lead to functional instability of the ankle complex $(5,16)$. A grade II injury indicates enough tearing of enough fibers within a structure for clinically detectable laxity. Some parts of the structure, however, must remain intact (14).

The natural healing ability of ligaments is variable, with some structures either having adequate compensatory mechanisms when injured or truly healing adequately (functionally), and some not (14). In the most severe complete injuries of either tendons or ligaments, retraction of torn ends leaves a gap that must be bridged. Some gaps are impossible, with many centimeters of space between the retracted muscle and tendon insertion sites onto the bone. Other differences are likely minimal, offering the potential for successful bridging by local repair responses (14). Immobilization, which results in an approximation of ends of torn ligaments, is considered a mainstay of treatment of ankle sprain, regardless of grade and type of immobilizer (6). Although elastic bandaging is still performed in so many hospitals for an acute ankle sprain, the awareness for reducing complications by using more rigid immobilizer has increased. Immobilization has the benefit of safety, immediate pain relief, and a feeling of security for the patients. However, it also means that muscle atrophy and stiffness will be more significant if the immobilization was prolonged (16).

Studies of ligament healing have traditionally been focused on surgical management and rehabilitation programs that include bracing and physical modalities. Advances in surgical techniques, rehabilitation exercises, and the design of assistive devices result from a better understanding of the biomechanical properties of ligaments and joints. Ligaments are sensitive to training and disuse. One of the original studies in this area, by Noyes et al., demonstrated that in the primates, eight weeks of cast immobilization of the lower limb resulted in substantial loss of strength in the knee anterior cruciate ligament (ACL). With a reconditioning program, it took close to one year for the ligament to attain $91 \%$ standard strength and $98 \%$ normal stiffness. Amiel et al. noted a close relationship between joint stiffness induced by immobilization and decrease glycosaminoglycans (GAGs) in joint tissues, as well as ligament atrophy (17). These findings suggested that early mobilization is crucial for a return to pre-injury activity. The quicker recovery in the semi-rigid cast group pointed up the advantage of using this material for a more rapid return to sport.

This study shows that semi-rigid casting provided a quicker recovery than an elastic bandage, as shown 
in the first week and second-week follow-up visits. Semi-rigid cast came up with more stability that is beneficial for protection and immobilization purposes to the sprained ligaments and surrounding tissues. However, the results of the fourth week were comparable between groups. This finding was explicable by the nature of the ligament healing in the fourth week after injury, in which the inflammation was subsided, regardless of any ligament elongation.

Prior studies had shown in general that the patient's satisfaction is decreased amid a rigid and nonremovable immobilizer application (18, 19). Differently, higher satisfaction rates were found in some technique using more rigid material, but better clinical outcomes $(20,21)$. Thus, it is essential to identify variables that influence overall satisfaction, including rigidity, clinical outcome, duration, and application ease. In this study, semi-rigid cast application yielded a comparable satisfaction with an elastic bandage. This result was partially due to the flexible feature of the semi-rigid cast, which permitting slight ankle dorsiflexion during partial weight-bearing. The ease of semi-rigid cast removal is also beneficial because of the usual discomfort resulting from regular cast removal. Kerkhoffs et al. stated that semi-rigid ankle support provided more stability and a quicker return to work and sport than an elastic bandage (22). The treatment of an ankle sprain using semi-rigid cast was cheaper to ankle brace mainly due to material costs in Indonesia (Rp170.000.00 \$10.83 vs. Rp671.000,00 \$42.77).

Insufficient treatment of ankle sprain may result in residual symptoms termed chronic ankle instability (CAI). Not only CAI limit physical activity, but CAI also leads to articular degeneration of the talus, and an increased risk of osteoarthritis. $(10,23)$ Authors of recent review determined that lateral ankle sprains contributed to $13 \%$ to $22 \%$ of all osteoarthritis cases involving the ankle and $80 \%$ of posttraumatic osteoarthritic cases $(2,24)$. In this study, there was no significant difference between ankle instability occurrences between groups. This is conceivably attributable to the minimal period of immobilization applied to both groups. Hubbard et al. had stated that ankle laxity did not significantly decrease over eight weeks which suggests that the lateral ligaments of the ankle need to be protected for longer than eight weeks if mechanical stability is to be restored after an acute sprain (25). Hence, regardless the material choice, insufficient period of immobilization may develop a disadvantageous result of ankle instability. Another clinically relevant variable to the degree of immobilization is the effect of gap size on ligament repair. Experimental studies have suggested that increasing gap sizes between disrupted ends leads to a structurally weaker scar. Ligaments are also shown to have some proprioceptive role in joint functioning.
Ligaments strains invoke neurologic feedback signals and appear to play a role in joint position sense (14). Thus, sufficient treatment will correlate with a prevention of functional instability.

This study had some limitations. The most important one was the small sample size. Despite the frequency of presentation, several patients, most who came to the emergency department, had to be excluded from the study because of the difficulty of following the study protocol in the emergency setting. The study could not be blinded to the authors because physicians had to treat patients directly. Future researches should bring in larger sample sizes, including analysis of semi-rigid casting efficacy on different durations and comparison with other treatment modalities comprehensively.

\section{CONCLUSION}

This study showed that immobilization for ankle sprains with a semi-rigid cast had better short-term results compared with an elastic bandage with shorter recovery time. Despite immobilizer material issues regarding comfortability, patient satisfaction was comparable between two groups with different material rigidity. Therefore, using a semi-rigid cast is beneficial for the treatment of acute ankle sprains.

However, ankle instability, as one of the outcomes of ankle sprain management comprises mechanical weakness and functional instability. Mechanical stability includes insufficient stabilizing structures and mobility that exceed physiological limits. Functional instability involves a feeling of giving way, resulted from proprioceptive deficits and impaired postural control in the joint. While this study showed a favorable short-term effect of the semi-rigid cast on grade II lateral ankle sprain related to the immobilization purpose, the functional stability associated with the physical therapy and exercise remains an issue to be analyzed. Further studies should include (1) optimal duration of semi-rigid cast application, (2) effect of adjunct physical therapy on ankle sprain management using semi-rigid cast; and (3) determinant of clinical outcomes among grade II lateral ankle sprain patients treated by semi-rigid casting.

Despite the study limitations, this study provided valuable outcomes and constructive for future studies.

\section{APPLICABLE REMARKS}

- It is advisable to use a semi-rigid cast for grade II lateral ankle sprain.

- This material yields a better short term outcome compared with an elastic bandage, and not being much costly when compared with an ankle brace.

\section{CONTRIBUTIONS}

First, second, and third authors: data collecting and analyzing. First author: manuscript writing and reference search. Second and third author: manuscript reviewing. 
CONFLICTS OF INTEREST

The authors declare no potential conflict of interest.
FUNDING

None.

\section{REFERENCES}

1. Waterman BR, Owens BD, Davey S, Zacchilli MA, Belmont PJ, Jr. The epidemiology of ankle sprains in the United States. J Bone Joint Surg Am. 2010;92(13):2279-2284. doi: 10.2106/JBJS.I.01537 pmid: 20926721

2. Herzog MM, Kerr ZY, Marshall SW, Wikstrom EA. Epidemiology of ankle sprains and chronic ankle instability. J Athl Train. 2019;54(6):603-610. doi: 10.4085/1062-6050-447-17 pmid: 31135209

3. Ekstrand J, Tropp H. The incidence of ankle sprains in soccer. Foot Ankle. 1990;11(1):41-44. doi: 10.1177/107110079001100108 pmid: 2210532

4. Kemler E, Krist MR IGL, Van de Port, Hoes AW G, Ardine de Wit. Economic evaluation of a soft ankle brace compared to tape in acute lateral ankle ligamentous sprains. Clin Res Foot Ankle. 2016;4. doi: 10.4172/2329910X.1000212

5. Hertel J. Functional instability following lateral ankle sprain. Sports Med. 2000;29(5):361-371. doi: 10.2165/00007256-200029050-00005 pmid: 10840868

6. Petersen W, Rembitzki IV, Koppenburg AG, Ellermann A, Liebau C, Bruggemann GP, et al. Treatment of acute ankle ligament injuries: a systematic review. Arch Orthop Trauma Surg. 2013;133(8):1129-1141. doi: 10.1007/s00402-013-1742-5 pmid: 23712708

7. Kaminski TW, Hertel J, Amendola N, Docherty CL, Dolan MG, Hopkins JT, et al. National athletic trainers' association position statement: conservative management and prevention of ankle sprains in athletes. J Athl Train. 2013;48(4):528-545. doi: 10.4085/1062-6050-48.4.02 pmid: 23855363

8. Malliaropoulos N, Papacostas E, Papalada A, Maffulli N. Acute lateral ankle sprains in track and field athletes: an expanded classification. Foot Ankle Clin. 2006;11(3):497-507. doi: 10.1016/j.fcl.2006.05.004 pmid: 16971243

9. Beynnon BD, Renstrom PA, Haugh L, Uh BS, Barker H. A prospective, randomized clinical investigation of the treatment of first-time ankle sprains. Am J Sports Med. 2006;34(9):1401-1412. doi: 10.1177/0363546506288676 pmid: 16801691

10. Hubbard TJ, Wikstrom EA. Ankle sprain: pathophysiology, predisposing factors, and management strategies. Open Access J Sports Med. 2010;1:115-122. doi: 10.2147/oajsm.s9060 pmid: 24198549

11. Avci S, Sayli U. Comparison of the results of short term rigid and semi-rigid cast immobilization for the treatment of grade 3 inversion injuries of the ankle. Injury. 1998;29:581-584. doi: 10.1016/S0020-1383(98)00129-6

12. Bilgic S, Durusu M, Aliyev B, Akpancar S, Ersen O, Yasar SM, et al. Comparison of two main treatment modalities for acute ankle sprain. Pak J Med Sci. 2015;31(6):1496-1499. doi: 10.12669/pjms.316.8210 pmid: 26870123

13. Zmurko MG, Belkoff SM, Herzenberg JE. Mechanical evaluation of a soft cast material. Orthopedic. 1997;20:693698.

14. Frank CB, Shrive NG, Lo IKY, Hart DA. Form and function of tendon and ligament. In: Einhorn TA, O'Keefe RJ, Buckwalter JA, editors. Orthopaedic basic science foundations of clinical practice third edition. Rosemont, IL: American academy of orthopaedic surgeons2007. 191-215 p.

15. Siegler S, Block J, Schneck CD. The mechanical characteristics of the collateral ligaments of the human ankle joint. Foot Ankle. 1988;8(5):234-242. doi: 10.1177/107110078800800502 pmid: 3366428

16. Clanton TO, McGarvey W. Athletic injuries to the soft tissues of the foot and ankle. In: Coughlin MJ, Mann RA, Saltzmann CL, editors. Surgery of the foot and ankle. Vol. III. Philadelphia, PA: Elsevier; 2007.

17. Ng GYF. Ligament injury and repair: Current concepts. Hong Kong Physioter J. 2002;20. doi: 10.1016/S10137025(09)70028-4

18. Louwerens JKG, Mensch DT, Verhoof OJW, de Reuver PR, Bijlsma TS, van Noort A, et al. Functional treatment for acute ankle sprains: Softcast wrap versus MOK-cast. A prospective randomized single-center trial. Foot Ankle Surg. 2019;25(4):482-487. doi: 10.1016/j.fas.2018.03.004 pmid: 30321958

19. Cohen AP, Shaw DL. Focused rigidity casting: A prospective randomised study. J R Coll Surg Edinb. 2001;46:265270.

20. Boyce SH, Quigley MA, Campbell S. Management of ankle sprains: a randomised controlled trial of the treatment of inversion injuries using an elastic support bandage or an Aircast ankle brace. Br J Sports Med. 2005;39(2):9196. doi: 10.1136/bjsm.2003.009233 pmid: 15665204

21. Lardenoye S, Theunissen E, Cleffken B, Brink PR, de Bie RA, Poeze M. The effect of taping versus semi-rigid bracing on patient outcome and satisfaction in ankle sprains: a prospective, randomized controlled trial. $B M C$ Musculoskelet Disord. 2012;13:81. doi: 10.1186/1471-2474-13-81 pmid: 22639864

22. Kerkhoffs GM, Struijs PA, Marti RK, Assendelft WJ, Blankevoort L, Van Dijk CN. Different functional treatment strategies for acute lateral ankle ligament injuries in adults. RCT. 2002;3:CD002938. doi: 10.1002/14651858.CD002938 
23. Hintermann B, Boss A, Schafer D. Arthroscopic findings in patients with chronic ankle instability. Am J Sports Med. 2002;30(3):402-409. doi: 10.1177/03635465020300031601 pmid: 12016082

24. Gribble PA, Bleakley CM, Caulfield BM, Docherty CL, Fourchet F, Fong DT, et al. Evidence review for the 2016 International Ankle Consortium consensus statement on the prevalence, impact and long-term consequences of lateral ankle sprains. Br J Sports Med. 2016;50(24):1496-1505. doi: 10.1136/bjsports-2016-096189 pmid: 27259753

25. Hubbard TJ, Cordova M. Mechanical instability after an acute lateral ankle sprain. Arch Phys Med Rehabil. 2009;90(7):1142-1146. doi: 10.1016/j.apmr.2009.01.020 pmid: 19577027 